\title{
3 IN 5 BABIES NOT BREASTFED IN THE FIRST HOUR OF LIFE
}

\section{BREASTFEEDING WITHIN AN HOUR AFTER BIRTH IS CRITICAL FOR SAVING NEWBORN LIVES}

\begin{abstract}
31 July 2018 News Release Geneva - An estimated 78 million babies - or three in five - are not breastfed within the first hour of life, putting them at higher risk of death and disease and making them less likely to continue breastfeeding, say UNICEF and WHO in a new report. Most of these babies are born in low- and middle-income countries.
\end{abstract}

The report notes that newborns who breastfeed in the first hour of life are significantly more likely to survive. Even a delay of a few hours after birth could pose life-threatening consequences. Skin-to-skin contact along with suckling at the breast stimulate the mother's production of breastmilk, including colostrum, also called the baby's 'first vaccine', which is extremely rich in nutrients and antibodies.

"When it comes to the start of breastfeeding, timing is everything. In many countries, it can even be a matter of life or death," says Henrietta H. Fore, UNICEF Executive Director. "Yet each year, millions of newborns miss out on the benefits of early breastfeeding and the reasons - all too often - are things we can change. Mothers simply don't receive enough support to breastfeed within those crucial minutes after birth, even from medical personnel at health facilities."

Breastfeeding rates within the first hour after birth are highest in Eastern and Southern Africa (65\%) and lowest in East Asia and the Pacific (32\%), the report says. Nearly 9 in 10 babies born in Burundi, Sri Lanka and Vanuatu are breastfed within the first hour. By contrast, only two in 10 babies born in Azerbaijan, Chad and Montenegro do so.*

"Breastfeeding gives children the best possible start in life," says Dr Tedros Adhanom Ghebreyesus, WHO DirectorGeneral. "We must urgently scale up support to mothers - be it from family members, health care workers, employers and governments, so they can give their children the start they deserve."

Capture the Moment, which analyzes data from 76 countries, finds that despite the importance of early initiation of breastfeeding, too many newborns are left waiting too long for different reasons, including:

- Feeding newborns food or drinks, including formula: Common practices, such as discarding colostrum, an elder feeding the baby honey or health professionals giving the newborn a specific liquid, such as sugar water or infant formula, delay a newborn's first critical contact with his or her mother.

- The rise in elective C-sections: In Egypt, caesarean section rates more than doubled between 2005 and 2014, increasing from $20 \%$ to $52 \%$. During the same period, rates of early initiation of breastfeeding decreased from $40 \%$ to $27 \%$. A study across 51 countries notes that early initiation rates are significantly lower among newborns delivered by caesarean section. In Egypt, only 19\% of babies born by C-section were breastfed in the first hour after birth, compared to $39 \%$ of babies born by natural delivery.

- Gaps in the quality of care provided to mothers and newborns: The presence of a skilled birth attendant does not seem to affect rates of early breastfeeding, according to the report. Across 58 countries between 2005 
and 2017, deliveries at health institutions grew by 18 percentage points, while early initiation rates increased by 6 percentage points. In many cases, babies are separated from their mothers immediately after birth and guidance from health workers is limited. In Serbia, the rates increased by 43 percentage points from 2010 to 2014 due to efforts to improve the care mothers received at birth.

Earlier studies, cited in the report, show that newborns who began breastfeeding between two and 23 hours after birth had a $33 \%$ greater risk of dying compared with those who began breastfeeding within one hour of birth. Among newborns who started breastfeeding a day or more after birth, the risk was more than twice as high.

The report urges governments, donors and other decision-makers to adopt strong legal measures to restrict the marketing of infant formula and other breastmilk substitutes.

The WHO and UNICEF-led Global Breastfeeding Collective also released the 2018 Global Breastfeeding Scorecard, which tracks progress for breastfeeding policies and programmes. In it, they encourage countries to advance policies and programmes that help all mothers to start breastfeeding in the first hour of their child's life and to continue as long as they want.

Available from: http://www.who.int/news-room/detail/31-07-2018-3-in-5-babies-not-breastfed-in-the-first-hourof-life 